\title{
The second observation of a live Trimuricea species (Octocorallia: Plexauridae)
}

Received: 30 September 2008/Accepted: 25 January 2009/Published online: 15 February 2009

(C) Springer-Verlag 2009

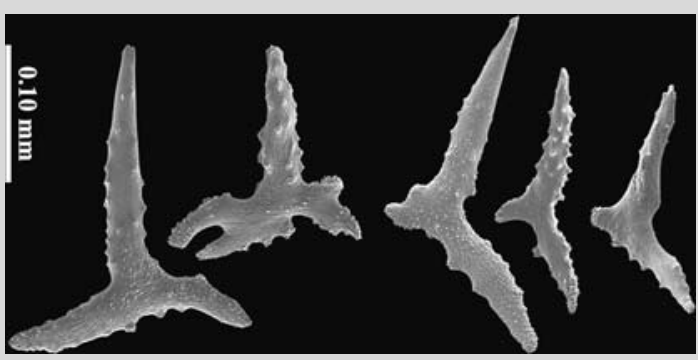

Fig. 1 Scanning electron micrographs of characteristic tripartite sclerites of Trimuricea

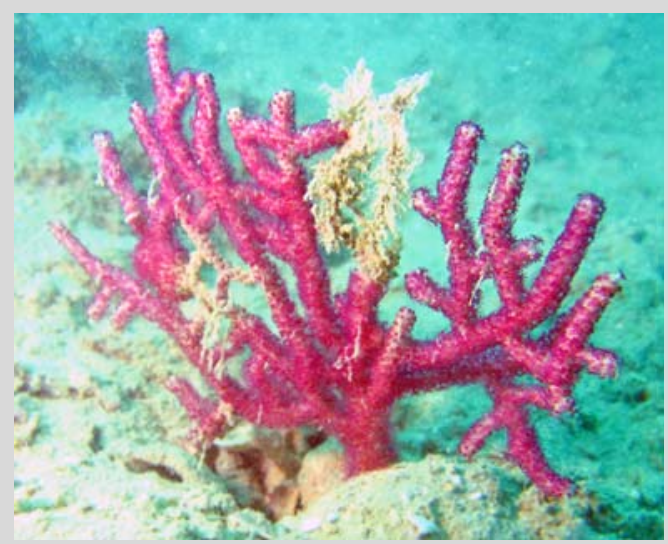

Fig. 2 A live colony of Trimuricea in Larak Island supported by the Iranian National Center for Oceanography (INCO) and Hormozgan University, specially Dr. V. Chegini and Dr. Kamrani are appreciated for their supports.

References

Gordon I (1926) Notes on a number of muriceid genera (Alcyonaria, Gorgonaceae), with special reference to spiculation. Proceedings of the scientific meetings of the Zoological Society of London, pp 509-531

Grasshoff M (1999) The shallow water gorgonians of New Caledonia and adjacent islands (Coelenterata: Octocorallia). Senckenb Biol 78(1/2):1-245 Grasshoff M, Bargibant G (2001) Coral Reef Gorgonians of New Caledonia. Institut de recherche pour le developpement, Paris

Thomson JA, Simpson JJ (1909) An account of the alcyonarians collected by the Royal Indian Marine Survey Ship Investigator in the Indian Ocean; with a report on the species of Dendronephthya by Henderson WD II. The alcyonarians of the littoral area. The Indian Museum, Calcutta

R. Samimi Namin $(\bowtie)$

Iranian National Center for Oceanography, Etemadzadeh St., Fatemi Ave., P. O. Box 14155-4181, Tehran, Iran e-mail: kaveh_s_n@yahoo.com

K. Samimi Namin · L. P. van Ofwegen

Nationaal Natuurhistorisch Museum, P.O. Box 9517, 2300 RA Leiden, The Netherlands

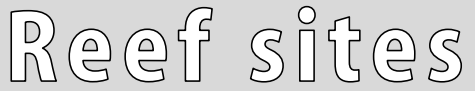

Coral Reefs (2009) 28:517

DOI $10.1007 / \mathrm{s} 00338-009-0471-2$ 